\title{
Disruption in the diabetic device care market
}

This article was published in the following Dove Press journal: Medical Devices: Evidence and Research

\author{
Utkarsh Ojha' \\ Raihan Mohammed ${ }^{2}$ \\ 'Faculty of Medicine, Imperial College \\ School of Medicine, Imperial College \\ London, London, UK; ${ }^{2}$ Department of \\ Medicine, University of Cambridge, \\ Cambridge, UK
}

\begin{abstract}
As diabetes mellitus (DM) has approached pandemic proportions, the pressure for effective glycemic management is mounting. The starting point for managing and living well with DM involves early diagnosis and monitoring blood glucose levels. Therefore, selfmonitoring of blood glucose (SMBG) can help patients maintain their blood glucose levels within the appropriate range. The general principle behind the current SMBG method involves a finger prick test to obtain a blood drop, which is applied onto a reagent strip and read by an automated device. Novel techniques are currently under evaluation to create the next generation of painless and accurate glucose monitoring for DM. We began by outlining how the emerging technology of the noninvasive glucose monitoring devices (NIGMDs) provides both economic and clinical benefits for health systems and patients. We further explored the engineering and techniques behind these upcoming devices. Finally, we evaluated how the NIGMDs disrupt the diabetic device care market and drive health care consumerism. We postulated that the NIGMDs play a pivotal role in the implementation of next generation of diabetes prevention strategies.

Keywords: medical devices, medical technology, diabetes management, innovation
\end{abstract}

\section{Introduction}

Diabetes mellitus (DM) is a metabolic disorder characterized by a chronic state of hyperglycemia. The global prevalence of DM has increased dramatically over the years. According to the 2014 World Health Organization (WHO) report, 422 million adults have DM, ${ }^{1}$ which will almost double by $2040 .{ }^{2}$ As DM has approached pandemic proportions, the pressure for effective glycemic management is mounting. Both hypo- and hyperglycemia pose risks for patients with DM. Hypoglycemia is often associated with overuse of antidiabetic medications, which can result in convulsions, coma and even death. Hyperglycemia can also cause severe impairment to the heart, kidneys and brain. The starting point for managing and living well with DM involves early diagnosis and monitoring blood glucose levels. Therefore, self-monitoring of blood glucose (SMBG) can help patients maintain their blood glucose levels within the appropriate range. Blood glucose testing costs $\sim £ 175$ million/year for the UK's National Health Service (NHS). ${ }^{3}$ Guidance regarding the frequency of SMBG varies. It is generally recommended that patients taking insulin should frequently monitor their blood glucose levels. The American Diabetes Association advises patients using insulin to test their blood glucose levels three to four times per day. ${ }^{4}$ In the UK, $>25$ blood glucose meters are marketed to patients and health care professionals. The general principle behind the current SMBG method involves a finger prick test to obtain a blood drop, which is applied onto a reagent strip and read by an automated
Correspondence: Utkarsh Ojha Faculty of Medicine, Imperial College School of Medicine, Sir Alexander Fleming Building, Imperial College London, Exhibition Road, London SW7 2AZ, UK

Tel +447759667685

Email utkarsh.ojhal3@imperial.ac.uk 
device. Novel techniques are currently under evaluation to create the next generation of painless and accurate glucose monitoring for DM.

\section{Limitations of the current SMBG technique}

Studies and guidelines highlight the importance of regular monitoring to maintain patients' glycemic status as close to the normal range as safely as possible. ${ }^{4}$ However, each test strip and lancet can only be used once and thus bears a significant economic burden for both health systems and patients. Between 2013 and 2014, 581 million blood glucose tests were undertaken in the UK at a weighted average cost of $£ 0.28$. $^{5}$ The current spending on blood glucose testing items per person in the Quality and Outcomes Framework (QoF) diabetes register is $£ 60.88 .{ }^{6} \mathrm{Clinical}$ commissioning groups are struggling to regulate these escalating SMBG costs, and SMBG is now a major contributor to NHS prescribing spending. For patients, the cost of test strips and needles has been associated with poor adherence to $\mathrm{SMBG},{ }^{7}$ increasing the risk of severe hypoglycemic episodes. Therefore, a noninvasive glucose monitoring device (NIGMD) has the potential to achieve significant efficiency savings for the NHS, without compromising care. A higher initial cost for the technology would be outweighed by greater cost savings using a reusable and more accurate device over a longer term.

Furthermore, current SMBG tests involve pricking the skin, typically on the finger, with the lancet. This process presents both a physical and mental barrier for diabetic patients. Pricking the fingertip four to ten times each day over several decades can cause scarring and loss of sensibility and perception. Burge ${ }^{8}$ reported that lancing pain and finger soreness, alongside cost, are leading reasons for self-reported patient noncompliance with physician's recommendations for SMBG. An NIGMD removes this physical and psychological barrier, improving patient compliance with respect to adequate glycemic control.

Finally, a major drawback of conventional SMBGs is the requirement to draw blood, thus increasing the risk of transmitting blood-borne infections. Over the past decade, diabetes prevalence has risen faster in low- and middleincome countries than in high-income countries. ${ }^{1}$ In these regions, conditions such as hepatitis and HIV predominate. Particularly, Africa has the highest WHO-estimated regional hepatitis $\mathrm{C}$ virus (HCV) prevalence of 5.3\%. ${ }^{9}$ Although many of these cases occur due to transmission by nondiagnostic causes (e.g., mother to fetus), an NIGMD would reduce all risks associated with fingerstick glucometers. Infection transmission is not just restricted to developing countries; bacterial contamination of glucose test strips by highly pathogenic organisms including methicillin-resistant Staphylococcus epiderdimis and Staphylococcus haemolyticus have been reported in Spain. ${ }^{10}$ Since 1990, at least 147 people have acquired HBV infection over 18 outbreaks in USA, each attributed to glucose monitoring practices. ${ }^{11}$ Both studies highlight that outbreaks from current SMBG practices are currently underestimated due to underreporting and underrecognition of acute infections. An NIGMD eliminates risks of blood-borne infection transmission, allowing safer blood glucose measurement to improve patient safety.

\section{Emerging NIGMDs}

Most current noninvasive technologies are still in the early stages of development. Blood is the most obvious candidate for measuring glucose; however, other more accessible biological fluids, including interstitial fluid (ISF), ocular fluid, sweat and urine, are also under investigation as sample media. These techniques are outlined in Table 1 and are classed by the same regulatory approval as conventional blood glucose measuring devices.

In USA, a Class III in vitro device (IVD), which includes glucose monitors, requires premarket application, including a 180-day review with clinical data to assess safety (risk of misdiagnosis due to false positive or false negative) and to demonstrate effectiveness. However, the 21st Century Cures Act legislation seeks to boost the efficiency, predictability and transparency of MedTech approval processes and creates an expedited pathway for breakthrough medical technologies, such as an NIGMD. ${ }^{12}$ In Europe, there has been much debate that device regulation in the UK is insufficiently robust, with negligent approval processes putting patients at risk. ${ }^{13}$ Manufacturers can place a CE mark on their product to show that the medical device has met the requirements of their national competent authority, i.e., the Medicines and Healthcare Products Regulatory Agency (MHRA) in the UK. However, these independent notified bodies do not necessarily require clinical trial data of calibration, testing and inspection and has led to weak independent surveillance of technology. Thus, new EU regulations for IVDs entered into force in May 2017 with a 3- and 5-year transition period for the new risk classification criteria and greater safety and performance requirements.

Any NIGMD should be accurate and ideally be suitable for all age groups and patients. This is challenging as most technologies indirectly estimate glucose and suffer from interfering factors, due to the complexity of human body 
Table I Current noninvasive glucose monitoring techniques

\begin{tabular}{|c|c|c|c|c|}
\hline Technique & & & Advantages & Disadvantages \\
\hline \multirow[t]{6}{*}{ Optical } & $\begin{array}{l}\text { Infrared } \\
\text { spectroscopy }\end{array}$ & $\begin{array}{l}\text { Beam of light with wavelength } 600-10,000 \mathrm{~nm} \\
\text { is focused on the body to measure glucose } \\
\text { in tissues }\end{array}$ & $\begin{array}{l}\text { Low scattering, low-cost } \\
\text { materials and good } \\
\text { penetration }\end{array}$ & $\begin{array}{l}\text { Hardware sensitivity and } \\
\text { stability and scanning } \\
\text { pressure required }\end{array}$ \\
\hline & Raman spectroscopy & $\begin{array}{l}\text { Assesses the scattering of a single wavelength } \\
\text { of light, which depends on vibrational or } \\
\text { rotational energy states within a molecule }\end{array}$ & $\begin{array}{l}\text { Sharper spectra and less } \\
\text { sensitive to temperature } \\
\text { changes }\end{array}$ & $\begin{array}{l}\text { Instability of laser } \\
\text { wavelength and low } \\
\text { signal:noise ratio }\end{array}$ \\
\hline & Fluorescence & $\begin{array}{l}\text { Absorption of light at a high wavelength and } \\
\text { emission of light at a lower wavelength, which } \\
\text { vary with glucose concentration }\end{array}$ & $\begin{array}{l}\text { Very sensitive. Little/no } \\
\text { damage to the body }\end{array}$ & $\begin{array}{l}\text { Scattering phenomena can } \\
\text { affect accuracy }\end{array}$ \\
\hline & $\begin{array}{l}\text { Surface plasmon } \\
\text { resonance } \\
\text { interferometry }\end{array}$ & $\begin{array}{l}\text { Sensor (metal surface covered in glucose- } \\
\text { sensitive ligand) is exposed to light, causing } \\
\text { variation in the generated plasmon (electron } \\
\text { wave) correlating with glucose concentration }\end{array}$ & $\begin{array}{l}\text { Rapid, real-time } \\
\text { monitoring of glucose } \\
\text { levels }^{17}\end{array}$ & $\begin{array}{l}\text { Limited to high molecular } \\
\text { weight biomolecules - } \\
\text { glucose requires complex } \\
\text { setup }\end{array}$ \\
\hline & $\begin{array}{l}\text { Optical coherence } \\
\text { tomography }\end{array}$ & $\begin{array}{l}\text { Measures the intensity of scattered/reflected } \\
\text { light, which changes with subcutaneous } \\
\text { glucose concentration }\end{array}$ & $\begin{array}{l}\text { High signal:noise ratio, } \\
\text { high resolution and good } \\
\text { penetration }\end{array}$ & $\begin{array}{l}\text { Sensitive to individual's } \\
\text { movement. Slightly affected } \\
\text { by temperature }\end{array}$ \\
\hline & $\begin{array}{l}\text { Photoacoustic } \\
\text { spectroscopy }\end{array}$ & $\begin{array}{l}\text { Light at a specific wavelength illuminates and } \\
\text { heats the tissue, causing volumetric expansion } \\
\text { and a detectable ultrasound pulse. Velocity } \\
\text { of the generated pulse changes with glucose } \\
\text { concentration }\end{array}$ & $\begin{array}{l}\text { Higher detection } \\
\text { sensitivity and } \\
\text { signal:noise ratio }\end{array}$ & $\begin{array}{l}\text { Sensitive to changes in } \\
\text { temperature and pressure }\end{array}$ \\
\hline \multirow[t]{2}{*}{ Transdermal } & $\begin{array}{l}\text { Impedance } \\
\text { spectroscopy }\end{array}$ & $\begin{array}{l}\text { Glucose is measured by its concentration- } \\
\text { dependent interaction with red blood cells } \\
\text { through an alternating current applied across } \\
\text { the skin (impedance) }\end{array}$ & $\begin{array}{l}\text { Differentiates between } \\
\text { extracellular and } \\
\text { intracellular fluids }\end{array}$ & $\begin{array}{l}\text { Requires } 60 \mathrm{~min} \text { of } \\
\text { equilibration process }\end{array}$ \\
\hline & $\begin{array}{l}\text { Reverse } \\
\text { iontophoresis }\end{array}$ & $\begin{array}{l}\text { Glucose molecules collect at the electrode } \\
\text { after a small current is applied across the skin }\end{array}$ & $\begin{array}{l}\text { Electrodes are easily } \\
\text { applied to the skin }\end{array}$ & $\begin{array}{l}\text { Skin irritation, inaccurate } \\
\text { and electrodes in place for } \\
60 \mathrm{~min}\end{array}$ \\
\hline \multirow[t]{2}{*}{ Electrochemical } & $\begin{array}{l}\text { Enzymatic detection } \\
\text { of glucose }\end{array}$ & $\begin{array}{l}\text { Electrodes coated with glucose oxidase react } \\
\text { with glucose to form proportional amounts of } \\
\text { hydrogen peroxide }\end{array}$ & $\begin{array}{l}\text { Specific frequencies can } \\
\text { differentiate between } \\
\text { glucose and glucose- } \\
\text { containing compounds }\end{array}$ & $\begin{array}{l}\text { Temperature influences } \\
\text { optimal investigation } \\
\text { frequency }\end{array}$ \\
\hline & Amperometry & $\begin{array}{l}\text { Sensor detects ions in body fluids through an } \\
\text { electric current (or change in current) }\end{array}$ & $\begin{array}{l}\text { Well commercialized. } \\
\text { Multiple sensors increase } \\
\text { accuracy }^{20}\end{array}$ & $\begin{array}{l}\text { Sensor error from drift, } \\
\text { calibration error and } \\
\text { delays }^{21}\end{array}$ \\
\hline \multirow[t]{2}{*}{ Others } & $\begin{array}{l}\text { Refractive changes in } \\
\text { the eye }\end{array}$ & $\begin{array}{l}\text { Measures the angle of rotation of polarized } \\
\text { light, which is proportional to glucose } \\
\text { concentration }\end{array}$ & $\begin{array}{l}\text { Low sensitivity to } \\
\text { scattering, so high } \\
\text { signal:noise ratio }\end{array}$ & $\begin{array}{l}\text { Practicality - requires } \\
\text { device to be fitted into eye }\end{array}$ \\
\hline & $\begin{array}{l}\text { Ultrasonic, } \\
\text { electromagnetic and } \\
\text { heat capacity }\end{array}$ & $\begin{array}{l}\text { Three independent, integrated techniques, } \\
\text { as in GlucoTrack, combined by a weighted } \\
\text { average of each }\end{array}$ & $\begin{array}{l}\text { Higher sensitivity than } \\
\text { normal spectroscopy } \\
\text { and a wide range of laser } \\
\text { light wavelength used }\end{array}$ & $\begin{array}{l}\text { Sensitive to interference } \\
\text { from other compounds and } \\
\text { temperature and pressure } \\
\text { changes }\end{array}$ \\
\hline
\end{tabular}

composition and the natural variation of physiological processes. For example, transdermal approaches are affected by variations in skin characteristics (age, type and color) and patch replacements can also increase costs. Device calibration, especially for electrochemical techniques, can also be long and complex, varying from 30 minutes to 3 hours.

Thus, there has been a shift to the integration of multiple methods, and studies have shown that combining multiple technologies and sensors increase the signal-to-noise ratio of glucose to other contributors, giving an improved accuracy of blood glucose level. ${ }^{14,15}$ Furthermore, developments in continuous glucose monitoring, using analytic approaches and closed-loop control algorithms, ${ }^{16}$ have improved the accuracy of these devices to almost finger-stick levels. Similar applications of NIGMDs to incorporate analytic approaches may also close the accuracy gap and expedite regulatory approval. The accuracy of any NIGMD should fall within clinically accepted zones compared to a finger-stick glucometer, e.g., using Pearson coefficient, Clarke error grid or mean absolute relative difference. Unless a device meets this minimum threshold for all types of diabetes, it should not be approved for commercial use. One example of this is the 
"GlucoWatch", which was the first NIGMD. Measurement was based on reverse iontophoresis of ISF through the skin. Although initially approved by the US Food and Drug Administration (FDA), it was later withdrawn from the market due to low accuracy, skin irritation and procedural problems.

As device accuracy remains elusive, currently, there is only one NIGMD that is available to the public; Abbott's FreeStyle Libre was granted FDA approval in September 2016. It uses sensors to measure glucose in the ISF using an electrochemical technique, which is one of three general categories of current NIGMD technologies (Table 1). The sensor costs $£ 57.95$ and lasts up to 14 days of continuous use, leading to costs of just over $£ 1,500$ per patient per year. However, two key devices are planned to enter the market in 2017/2018, and we estimate that the resulting competition will drive down prices.

SugarBEAT uses a transdermal and electromagnetic technique to draw glucose from the ISF onto an adhesive skin patch. It is marketed as being suitable for people with Type I diabetes, Type II diabetes and prediabetes, has recently received a $\mathrm{CE}$ approval and is anticipated to be launched in early 2018 in the UK. GlucoTrack measures glucose levels using three different technologies: ultrasonic, electromagnetic and thermal sensors. Each measurement is then combined via a proprietary algorithm to calculate the weighted average of the patient's glucose level. The device has received a CE approval and is intended for people with prediabetes and Type II diabetes but is not yet marketed in the EU/UK.

Other products are currently in clinical trials and are expected to come to market in the next 3-5 years. GlucoWise uses high-frequency $(65 \mathrm{GHz})$ radio waves and nanocomposite films on the sensor to penetrate through tissues. NovioSense is a spring-like coil inserted under the lower eyelid that uses enzymatic action to detect glucose levels in tears. Finally, iQuickit and Glucose Pop Test devices use enzymatic action to detect glucose in saliva; however, there are concerns about how well the glucose levels in saliva and tears correlate with capillary blood glucose. We also have reservations about how keen potential users will be on a subconjunctival implant, especially with regard to children.

Recently, large tech companies, including Google and Apple, have entered this market with a view to revolutionize NIGMDs. The Google X lab and Novartis have collaborated on smart contact lenses, and Microsoft has designed sensory electrodes that could detect glucose when incorporated into flexible hydrogels. Thus, there is a significant market potential for NIGMDs and the technology is beginning to catch up.

\section{Disruptive innovation}

In 2016, the global diabetic care device market was valued at $\$ 19.05$ billion..$^{22}$ This valuation is estimated to reach $\$ 27.42$ billion by $2022 .{ }^{23}$ The increasing prevalence of DM is the key driver for this trend, fueling the growth of the global SMBG device market at a compound annual growth rate (CAGR) of $12 \%$ (Figure 1). ${ }^{22}$ Bower and Christensen described "disruptive technologies" as entities that revolutionize an existing saturated business, much like the current SMBG market. ${ }^{24}$ The NIGMDs create a new market and value network that could not only disrupt but also replace current test strips. Furthermore, in some emerging markets including China and India, governmental support for health care and insurance is increasing and becoming more widespread. ${ }^{25}$ In these countries, the diabetic population is among the highest in the world; ${ }^{26}$ consequently, spending on diabetes treatment constitutes a large proportion of total medical expenditure. ${ }^{24}$ These long-term macro fundamentals will therefore continue to fuel demand in the health care market, providing favorable economic conditions for developing technological innovations, such as the NIGMDs.

Larger companies generally work with sustaining technologies, which rely on incremental improvements to previously established products. Disruptive innovations require large capital investment and divert scarce resources for improving the accuracy and reliability of current products against current competition. This is especially true in the SMBG business environment of tight profit margins and declining test strip prices. ${ }^{27}$ As a result, larger firms rarely capitalize on the potential efficiencies, synergies or new marketing provided by disruptive technologies. Consequently, smaller biotech firms are given an opportunity to compete with larger companies and enter a competitive market through product differentiation.

Currently, just four companies - Roche Diagnostics, LifeScan, Bayer Healthcare Division and Abbott Laboratories - control $90 \%$ of the global diabetic care device market. Although these market leaders are dissuaded from pursuing disruptive innovations for the aforementioned reason, they may seek to acquire emerging technologies through mergers and acquisitions (M\&A) to drive efficacy in health care. Indeed, the current economic conditions favor health care M\&A activity, which has grown at a 50\% CAGR from 2012 to $2015,{ }^{28}$ over twice as fast as overall M\&A activity. This pattern is largely attributed to historically low interest rates, ${ }^{29}$ which is being used strategically for debt financing. This increase in corporate leverage is driving financial engineering (i.e., buy- 


\section{Global SMBG market}

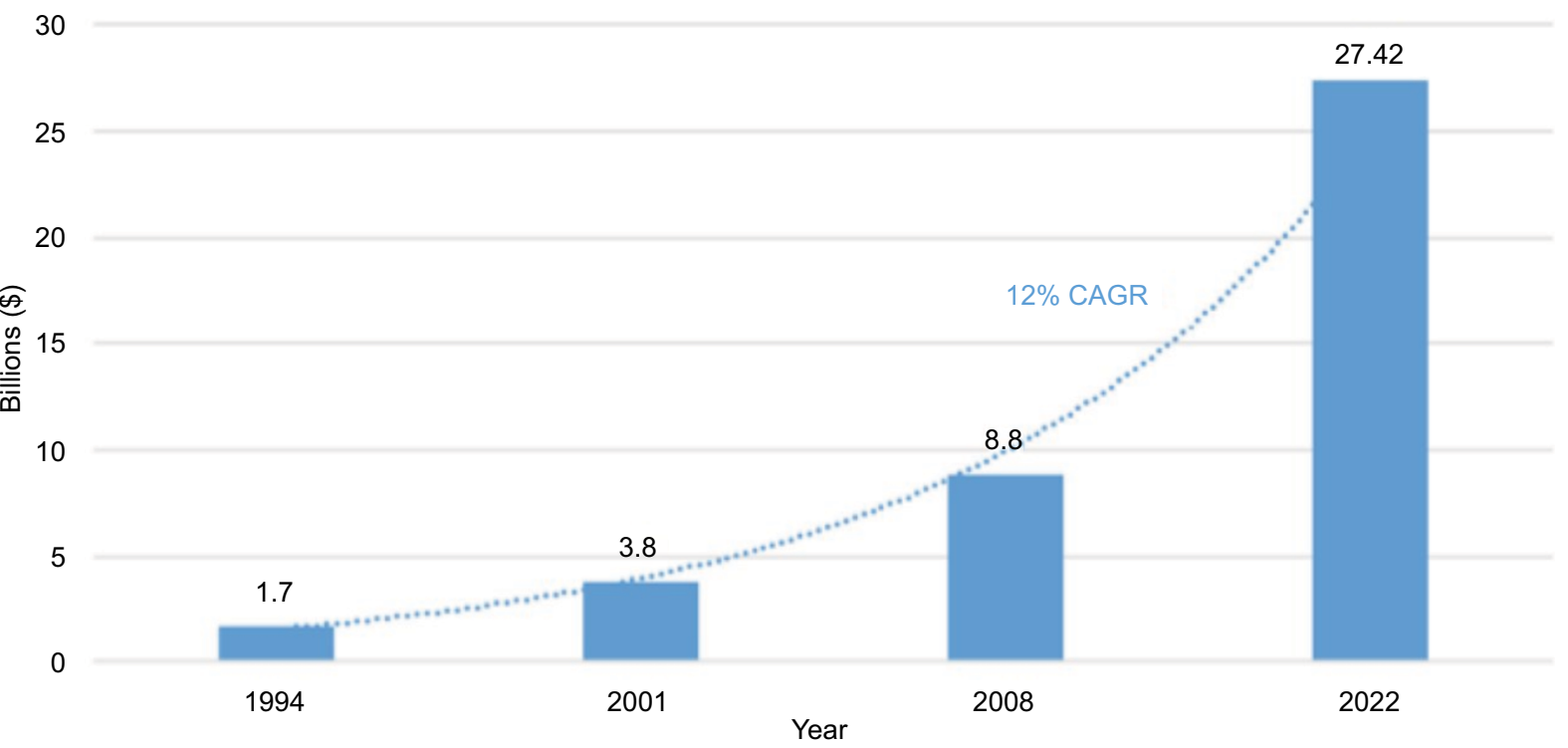

Figure I Global sales of SMBG products.

Notes: Sales in SMBG devices were $\sim \$ 1.7$ billion in 1994. By 2000 , the market climbed to $\$ 3.8$ billion, and by 2008 , global sales reached $\$ 8.8$ billion. It is estimated by 2022 , sales will reach $\$ 27.42$ billion at a CAGR of $12 \%$ since 1994 . Data from Visiongain. ${ }^{23}$

Abbreviations: SMBG, self-monitoring of blood glucose; CAGR, compound annual growth rate.

ing rival companies). Conventional use of cash by companies, such as paying debt and dividends can be regarded as "doing nothing" by company shareholders. Therefore, in order to maintain shareholders' interest, company boards may be more inclined to exploit low interest to fund inorganic expansion. Hence, global MedTech M\&A activity will continue at pace and intensify competition between large health care corporations to acquire disruptive technologies.

\section{Perspectives and concluding remarks}

In order to reduce the financial burden on health systems, policy makers are now focusing their attention on implementing effective prevention programs. The use of mobile phone messaging has shown great promise in delivering personalized advice and tackling diabetes prevention. In a randomized control trial by Ramachandran et al, ${ }^{30}$ men with impaired glucose tolerance were assigned into either a control arm, receiving standard diabetic care advice, or an interventional arm, receiving personalized advice via mobile phone messaging. The group reported that the cumulative incidence of Type II DM was lower in those receiving mobile phone messages. Although the study is limited to Indian males, the authors provide compelling insight into how technology can shape more successful avenues for preventing diabetes. New technologies are being developed that couple blood glucose monitoring devices to mobile phone applications and send blood glucose levels to patients' mobile phones, allowing them to keep track of their progress. Each patient therefore receives recommendations about managing their diabetes, which is tailored to their needs. Bibbings et $\mathrm{al}^{31}$ tested the accuracy of an NIGMD based on a smartphone application that uses artificial neural network to detect blood glucose levels. The authors showed that this technique is capable of accurately measuring both low and high blood glucose levels. Recently, a new blood glucose monitoring meter, the Contour ${ }^{\circledR}$ Next One, has been engineered, which can be linked via Bluetooth connectivity to smartphones. Christiansen et $\mathrm{al}^{32}$ reported that this new device shows analytical and clinical accuracy and is easy to use in clinical settings among patients who have never used blood glucose monitoring devices previously.

The availability of a device for rapid assessment of blood glucose levels without skin puncture will not only revolutionize glucose monitoring at home and hospitals but also significantly disrupt the SMBG market space. In the UK, an NIGMD would achieve the greatest benefit per pound spent by NHS and reduce escalating SMBG costs. Clinically, patient compliance would increase alongside eliminating the risk of blood-borne infection transmission. It is conceivable that an NIGMD will play a pivotal role in the implementation of next generation of prevention strategies.

\section{Author contributions}

UO and RM were involved in the conception, design, drafting, revising and final approval of the article. 


\section{Disclosure}

The authors report no conflicts of interest in this work.

\section{References}

1. World Health Organization [webpage on the Internet]. World Health Organization. Global Report on Diabetes. Available from: http://www. who.int/diabetes/global-report/en/. Accessed November 25, 2016.

2. International Diabetes Federation [webpage on the Internet]. IDF Diabetes Atlas-7th. Available from http://www.diabetesatlas.org/. Accessed November 25, 2016.

3. Butalia S, Rabi DM. To test or not to test? Self-monitoring of blood glucose in patients with type 2 diabetes managed without insulin. Open Med. 2010;4(2):114-116.

4. American Diabetes Association. Standards of medical care in diabetes - 2014. Diabetes Care. 2014;37(suppl 1):S14-S80.

5. Leigh S, Idris I, Collins B, Granby P, Noble M, Parker M. Promoting health and reducing costs: a role for reform of self-monitoring of blood glucose provision within the National Health Service. Diabet Med. 2015;33(5):681-690.

6. Hill J, Hicks D, James J, et al. Blood Glucose Monitoring Guidelines. Brixworth: Training, Research and Education for Nurses in Diabetes (TREND-UK); 2017. Available from: http://trend-uk.org/wp-content/ uploads/2017/02/170106-TREND_BG_FINAL.pdf. Accessed January 25, 2018.

7. Vincze G, Barner J, Lopez D. Factors associated with adherence to selfmonitoring of blood glucose among persons with diabetes. Diabetes Educ. 2004;30(1):112-125.

8. Burge M. Lack of compliance with home blood glucose monitoring predicts hospitalization in diabetes. Diabetes Care. 2001;24(8):1502-1503.

9. Pybus OG, Drummond AJ, Nakano T, Robertson BH, Rambaut A. The epidemiology and iatrogenic transmission of hepatitis C virus in Egypt: a Bayesian coalescent approach. Mol Biol Evol. 2003;20(3):381-387.

10. Pérez-Ayala M, Oliver P, Cantalejo F. Prevalence of bacterial contamination of glucose test strips in individual single-use packets versus multi-use vials. J Diabetes Sci Technol. 2013;7(4):854-862.

11. Thompson N, Perz J. Eliminating the blood: ongoing outbreaks of hepatitis B virus infection and the need for innovative glucose monitoring technologies. J Diabetes Sci Technol. 2009;3(2):283-288.

12. FDA [webpage on the Internet]. 21st Century Cures Act; 2017. Available from: https://www.fda.gov/RegulatoryInformation/LawsEnforcedbyFDA/SignificantAmendmentstotheFDCAct/21stCenturyCuresAct/ default.htm. Accessed October 30, 2017.

13. Horton R. Offline: the scandal of device regulation in the UK. Lancet. 2017;379(9812):204.

14. Harman-Boehm I, Gal A, Raykhman AM, Naidis E, Mayzel Y. Noninvasive glucose monitoring: increasing accuracy by combination of multi-technology and multi-sensors. J Diabetes Sci Technol. 2010;4(3):583-595.

15. Sobel SI, Chomentowski PJ, Vyas N, Andre D, Toledo FGS. Accuracy of a novel noninvasive multisensor technology to estimate glucose in diabetic subjects during dynamic conditions. J Diabetes Sci Technol. 2014;8(1):54-63.

16. Facchinetti A. Continuous glucose monitoring sensors: past, present and future algorithmic challenges. Sensors. 2016;16(12):2093.
17. Miyazaki C, Shimizu F, Mejía-Salazar J, Oliveira O, Ferreira M. Surface plasmon resonance biosensor for enzymatic detection of small analytes. Nanotechnology. 2017;28(14):145501.

18. Poddar R, Andrews JT, Shukla P, Sen P [webpage on the Internet]. NonInvasive Glucose Monitoring Techniques: A Review and Current Trends. Cornell University Library: arXiv:0810.5755 [physics.med-ph]. Available from: http://arxiv.org/abs/0810.5755. Accessed October 30, 2017.

19. Vashist S. Non-invasive glucose monitoring technology in diabetes management: a review. Anal Chim Acta. 2012;750:16-27.

20. Castle JR, Pitts A, Hanavan K, et al. The accuracy benefit of multiple amperometric glucose sensors in people with type 1 diabetes. Diabetes Care. 2012;35(4):706-710.

21. Castle JR, Kenneth Ward W. Amperometric glucose sensors: sources of error and potential benefit of redundancy. J Diabetes Sci Technol. 2010;4(1):221-225.

22. Scalar Market Research. Diabetes Care Devices Market, by Type (Blood Glucose Monitoring Devices, Insulin Delivery Devices), End-users (Hospitals, Homecare, Others) - Global Revenue, Trends, Growth, Share, Size and Forecast to 2022. 2016. Available from: https://www. scalarmarketresearch.com/market-reports/diabetes-care-devicesmarket. Accessed January 25, 2018

23. Visiongain. Self Monitoring Blood Glucose Devices: World Market Outlook 2012-2022. London: Visiongain; 2012. Available from: https:// www.visiongain.com/Report/927/Self-Monitoring-Blood-GlucoseDevices-World-Market-Outlook-2012-2022. Accessed January 26, 2018.

24. Bower JL, Christensen CM. Disruptive technologies: catching the wave. Harv Bus Rev. 1995;73:43-53.

25. PWC. The Digital Healthcare Leap. UK: PricewaterhouseCoopers LLP; 2017. Available from: https://www.pwc.com/gx/en/issues/high-growthmarkets/assets/the-digital-healthcare-leap.pdf. Accessed January 25, 2018.

26. Yesudian CA, Grepstad M, Visintin E, Ferrario A. The economic burden of diabetes in India: a review of the literature. Global Health. 2014;10:80.

27. Hughes MD. The business of self-monitoring of blood glucose: a market profile. J Diabetes Sci Technol. 2009;3(5):1219-1223.

28. Jain N, Kapur V, Klingan F, Murphy K, Biesen T, Weisbrod J. Global Healthcare Corporate M\&A Report 2016. Boston, MA: Bain \& Company; 2016.

29. Miller M [webpage on the Internet]. Fed's Williams Says Historically Low Interest Rates Will Persist; 2017. Available from: https://www. bloomberg.com/news/articles/2017-02-21/fed-s-williams-says-historically-low-interest-rates-will-persist Accessed October 30, 2017.

30. Ramachandran A, Snehalatha C, Ram J, et al. Effectiveness of mobile phone messaging in prevention of type 2 diabetes by lifestyle modification in men in India: a prospective, parallel-group, randomised controlled trial. Lancet Diabetes Endocrinol. 2013;1(3):191-198.

31. Bibbings K, Wood D, Wood R, Martini L, Bennett A. Accuracy of non-invasive glucose monitoring using advanced mobile phone neural network technology-part 1. Bioepic Limited. 2017. Available from: https://epichealth.io/wp-content/uploads/2017/09/Epic-App-AccuracyStudy-Part-1-1.pdf. Accessed November 16, 2017.

32. Christiansen M, Greene C, Pardo S, et al. A new, wireless-enabled blood glucose monitoring system that links to a smart mobile device: accuracy and user performance evaluation. $J$ Diabetes Sci Technol. 2017;11(3):567-573.
Medical Devices: Evidence and Research

\section{Publish your work in this journal}

Medical Devices: Evidence and Research is an international, peerreviewed, open access journal that focuses on the evidence, technology, research, and expert opinion supporting the use and application of medical devices in the diagnosis, monitoring, treatment and management of clinical conditions and physiological processes. The identification of novel

\section{Dovepress}

devices and optimal use of existing devices which will lead to improved clinical outcomes and more effective patient management and safety is a key feature. The manuscript management system is completely online and includes a quick and fair peer-review system. Visit http://www. dovepress.com/testimonials.php to read real quotes from authors. 